\title{
(息)
}

Citation:

Hardwell, AG (2013) The demise of the outdoor apprenticeship. In: Adventure Tourism: Meanings, experience and learning. Contemporary Geographies of Leisure, Tourism and Mobility . Routledge, pp. 115-133. ISBN 9780415524834,9780203120095

Link to Leeds Beckett Repository record:

https://eprints.leedsbeckett.ac.uk/id/eprint/3545/

Document Version:

Book Section (Accepted Version)

Permission granted by Routledge to deposit chapter on 28/03/2017

The aim of the Leeds Beckett Repository is to provide open access to our research, as required by funder policies and permitted by publishers and copyright law.

The Leeds Beckett repository holds a wide range of publications, each of which has been checked for copyright and the relevant embargo period has been applied by the Research Services team.

We operate on a standard take-down policy. If you are the author or publisher of an output and you would like it removed from the repository, please contact us and we will investigate on a case-by-case basis.

Each thesis in the repository has been cleared where necessary by the author for third party copyright. If you would like a thesis to be removed from the repository or believe there is an issue with copyright, please contact us on openaccess@leedsbeckett.ac.uk and we will investigate on a case-by-case basis. 


\section{THE DEMISE OF THE OUTDOOR APPRENTICESHIP}

Full Reference: Hardwell, A. G. (2013) The Demise of the Outdoor Apprenticeship in S. Taylor, P. Varley, and T. Johnston (eds), Adventure Tourism: Meanings, experience and learning, London: Routledge, pp. 115 - 133.

\section{INTRODUCTION}

Sociologists study the way in which humans interact with each other within societies. In studying the intricacies of human behaviour, greater understanding of society as a whole is possible. Donnelly (1981: 568) posed questions over a quarter of a century ago that may still be important today: "How is society possible? How and why do people develop the sets of norms, values and sanctions that are manifested as socially acceptable behaviour and, for the most part, conform to them?" He goes on to suggest two reasons for wanting to study smaller units or subcultures of society: they are interesting cultural phenomena but they can also give important insight into society. Sport sociologists have similar concerns albeit focused upon how generic concepts taken from broader societal studies either play out in or are evidenced within microcosms of sport. Therefore, any sport with both a long tradition and a recent history of current innovation and expansion provides a perfect opportunity to explore sociological concepts. This gave purpose to this chapter which is to recognise that recent history in the differentiated nature of rock climbing in the UK has begun to shape this activity and allow wider participation from varied interests and backgrounds.

This chapter has two important aims. The first is to give an overview of UK rock climbing, its practices and subcultural issues. UK rock climbing is briefly described to the reader. In doing this it draws first on traditional rock climbing in the UK as a particular style of climbing and then on more contemporary practices. This is because traditional climbing forms the back drop to rock climbing in the UK. It is the type of climbing with which the majority of UK participants are familiar. Traditional climbing embodies a style of ascent 
towards which many rock climbers aspire. It is the most psychologically taxing and risky rather than the most difficult type of ascent. It then juxtaposes this rock climbing type with more contemporary rock climbing practices. These 'new ways' of climbing and their effect on subculture and practices are then explored.

Its second aim involves the focus of attention of this book. Adventure tourism in the UK will provide an important context in critically analysing the possible benefits of shifts through contemporary rock climbing practices and how the latter has shaped rock climbing activity in the UK. A line of inquiry will be developed suggesting the appropriation (Marchart 2004) of rock climbing into mainstream society through contemporary climbing practices. A focus on technical climbing ability is now occurring to the detriment of traditional rock climbing skills and the outdoor apprenticeship essential to its safe practice. Not only is contemporary climbing shaping the very values of traditional climbing but it is also allowing greater diversity of acceptable rock climbing practices in traditional rock climbing. These changes have improved accessibility to many different and diverse user groups providing business opportunities in the outdoors. While this allows rock climbing to be developed as an excellent adventure tourism activity a loss of traditional rock climbing skill and general outdoor awareness has occurred and these tensions forms the chapter's content. To this end it is a unique attempt to understand the changes within rock climbing and allow a counter gaze (Lim, 2008) from within the activity itself. It therefore asks the reader to go beyond the benefits of the commercial world of adventure tourism products and services and consider possible impacts of greater rock climbing accessibility through appropriation.

\section{UK ROCK CLIMBING PRACTICES}


Rock climbing has captured the imagination of participants for many different reasons over the last two decades. It has become one of the fastest growing outdoor pursuits in the UK during this period (British Mountaineering Council [BMC], 2003). It now has many coexisting facets all displaying obvious differences. Traditional climbing, sport climbing, bouldering, indoor climbing, deep water soloing and competition climbing are recognisable manifestations of types of rock climbing in the twenty first century. Ethics, practices and even subcultures of each rock climbing type can be identified but all share the ultimate goal of ascending a climb from the ground to its top using equipment as a safeguard only to falling.

Two types of UK rock climbing practice will be explained: traditional and contemporary. The former represents the historical rock climbing legacy in Britain and alludes to a certain style of climbing where ascents are made from the ground up with minimal information about the climb always with the 'end game' in mind of using equipment as a safeguard only to a fall. This is known as an 'on sight' or 'flash' ascent and is often seen as one of the most coveted styles of ascent by climbers. All British rock climbing types stem from 'traditional climbing'. Contemporary rock climbing in this chapter alludes to indoor climbing, sport climbing and bouldering all of which focus on technical rock climbing movement (see Hardwell 2009). These 'rock' climbing types focus on the 'end game' already mentioned but worry less about the means to the end due to the highly technical nature of the rock climbing.

\section{Traditional climbing}

Traditional climbing usually takes place in pairs. Each person ties onto either end of a rope 50 metres long. Using a special locking mechanism on the rope known as a belay device one person can feed the rope out to his partner who begins ascending. Traditional climbing uses 
removable equipment placed in natural fissures in the rock in order to protect the climber from a ground fall. The skills required for traditional climbing include route finding, interpreting and 'reading' the rock, interpreting guidebook information, placing equipment in the rock and constructing belays or anchor points to allow safe passage of high rock climbs. In the UK longer climbs are often found in mountain areas and these draw on general outdoor skills (for a fuller explanation see Lewis, 2004, Donnelly, 2003: 291-304 and Hardwell, 2007: 12-14).

Traditional climbs have many unknowns; route choice, equipment used, route conditions, weather and so on and this often results in a compromise in difficulty ensuring climbs are commensurate with capabilities and all possible variables. The aim of all climbing is a safe ascent and when traditional climbing this may require retreat with dignity (Mortlock 1984). Traditional climbing is psychologically as well as physically testing because the lead climber may often be at risk of a considerable fall before the rope comes into play and relies on the quality of removable protection placed while climbing to prevent a ground fall.

From traditional climbing recognisable ethical codes or 'canons' have developed across climbing types. Rock climbing has no rule book. Using equipment to gain a hold is not a punishable offence. Each climber ascends knowing they will not be berated for poor style as long as honesty is foremost. Yet, at the same time, they are acutely aware of codes of practice stemming from traditional climbing. It is also worth noting that the technical nature of the most difficult traditional rock climbs in the UK is so high that climbers who attempt these deem it necessary to practise them beforehand, an approach more generally adopted by contemporary climbing types. This has led to an interesting paradox. Those setting traditional rock climbing standards in the UK and admired by other rock climbers have, in many cases, 
adopted codes and canons of contemporary climbing because of the extreme difficulty of the climb.

\section{Contemporary climbing}

Other climbing types have taken the 'end game' of rock climbing (ascending rock climbs using equipment as a safeguard only to a fall) and used this as a climbing focus. Their aim is to test physical rock climbing skills through attempting technically difficult climbs or shorter boulder 'problems'. Often these are so difficult the climb has to be practised beforehand for the 'end game' to be achieved. This is the domain of the boulderer and sport climber. In sport climbing regularly placed permanently fixed protection points in the form of expansion bolts take the place of removable chocks. Each climb is identified from below by a line of bolts often placed in seemingly blank rock walls. A different grading system developed in France referring only to technical difficulty is used. The grade indicates the most technically difficult move on the climb but gives no indication of danger because fixed protection is regularly available often rendering the climb relatively safe, given correct use of equipment.

Donnelly (2003: 292) describes the different approaches adopted by traditional and more contemporary climbing practices, particularly sport climbing, as the "great divide" and suggests it is the "most serious rift in the history of the sport". While this rift is documented and explored in terms of different climbing approaches little understanding of its complexity in British rock climbing exists and investigation into the possible development of a cultural shift away from adventure towards more predictable and known outcomes is occurring (Hardwell, 2007). This possible change in emphasis may be a legacy of contemporary approaches to UK rock climbing. Climbing approaches changed significantly from the 1970s (Hankinson, 1988). A far more systematic and 'sport-like' approach was adopted (Jones \& 
Milburn, 1988) and a relaxation of established ethical codes occurred in favour of a focus on the practices required to complete technically demanding rock climbs safely.

\section{FRAME CONDITIONS}

Such changes require contextualisation to allow more comprehensive understanding. Poon's (1993) broad overview of touristic changes can be used to explore the wider 'frame conditions' associated with traditional and contemporary climbing eras. In any time period various frame conditions outside of rock climbing will assist its development in a particular direction. Those activists at the very core of rock climbing sub-culture (see Hardwell, 2009) will drive the activity forward in accordance with the zeitgeist created through the frame conditions. These influences can be summarised by the classic external environment analysis of political, economic, social and technological aspects and are represented thematically in Figures 1 and 2. Focusing on climbing practices between 1950 and 1965 allows insight into an era of climbing where equipment, although vastly improved from the pre Second World War era, was still rudimentary and specific training was rarely deployed. It was an era dominated by strong traditional rock climbing ethics in keeping with the frame conditions of the time. This contrasts greatly with the 1970s and beyond.

\section{Traditional frame conditions}

The existence of climbing clubs and the difficulty of accessing these, particularly for women, allowed for an exclusive feel to climbing where gaining access to the activity required antics, behaviours and activities (Perrin, 2004, Hankinson, 1988). There has always been fierce rivalry at the higher echelons of rock climbing yet the overwhelming feel from the many sources commenting on this era is the importance of camaraderie and the intrinsic worth of being associated with the environment (Lewis, 2004; Perrin, 2004; Wilson, 1998; Drasdo, 
1996; Gray, 1993, 1993a; Hankinson, 1988; Birkett, 1983). Importantly, rock climbers had little choice regarding the style of ascent; traditional rock climbing was the only style on offer and mountain crags were particularly popular. An outdoor apprenticeship was therefore a prerequisite for safe climbing with longer climbs calling for serious climbing commitment.

\section{Contemporary frame conditions}

The marked contrast between the traditional and contemporary climbing eras is that of choice. Heywood (1994) neatly sums this up by commenting that:

the danger, the unpredictability, the risk, the irrationality of climbing are substantially matters of choice; climbers can have their activity raw, medium or well-done according to how they feel or what they want from the sport (Heywood 1994:187)

The attention focus is the physical difficulty of rock climbing movement and this can be achieved indoors or outside. Often physical rock climbing ability far outweighs general outdoor experience. Accessible venues are available and sought after to allow the pursuit of technical difficulty. Different practices are deployed at the expense of traditional rock climbing ethics to allow high standard technical difficulty with safety in mind. Last (1997) has noted higher incidents of top rope practices in outdoor venues. Skills associated with traditional rock climbing have been neglected in favour of technical rock climbing ability. Yet, this style of climbing neatly fits post-modern lifestyles (Jenks, 2005). Indoor climbing and bouldering can both be time bound and compliment busy lifestyles. They are social activities where public displays of climbing occur. For many they provide important escapes from routine and allow people to experience a different social situation and activity (Hardwell, 2009). Contemporary climbing is not an activity solely for outdoor enthusiasts but 
for anyone wishing to pursue an alternative pastime. For many, indoor climbing is an activity in its own right rather than a progression to other climbing pursuits (ibid).

\section{THE SUBCULTURAL NATURE OF ROCK CLIMBING IN THE UK}

Rock climbing has been viewed as a recognisable subculture within society (Lewis, 2004; Donnelly, 2003; Kiewa, 2002; and importantly Donnelly and Young, 1988). Subcultural tensions occur inside and outside of rock climbing. According to Thornton (1997):

The defining attributes of 'subcultures', then, lies with the way the accent is put on the distinction between a particular culture/social group and the larger culture/society. The emphasis is on variance from a larger collectivity who are invariably but not unproblematically, positioned as normal, average and dominant (Thornton 1997: 5).

Hebdige, (1987: 85) through many counter-cultural studies accepted important contributors to social stability, suggested "a credible image of social cohesion can only be maintained through the appropriation and redefinition of cultures of resistance". This he sees as a "cyclical process leading from opposition to diffusion, from resistance to incorporation and encloses each successive subculture" (ibid: 100). Beal and Crosset (1997: 75) concluded that “truly counter-cultural groups do not exist for long". Donnelly (1993) documented the demise of climbing as a recognisable counter or subculture understanding the outside pressures and inner tensions that would eventually cause its demise.

Contemporary subcultural work (Jenks 2005) and post-subcultural contributions (Macbeth 2005; Marchart 2004; Weinzierl and Muggleton 2004; Kiewa 2002) problematise the heterogeneity of both society and its subcultures. Jenks $(2005 ; 135)$ observes that “contemporary society's multiple manifestations are now in such a flux and constant state of 
proliferation that our real problem resides in attempting to theorize what... we previously referred to as the "centre"'. Macbeth (2005) extends such ideas to subcultures themselves believing two key challenges confront research into sport subcultures:

At the micro level, analysis of sport subcultures needs to explore heterogeneity amongst its members and reveal the multiple, and sometimes conflicting, identifies formed by individuals and groups within subcultures. Internal tensions and power relations between groups need to be analysed as sites of subcultural production and examined in the context of the subcultures' dynamic relations within the dominant culture at the macro-level (Macbeth 2005: 5).

To view rock climbing as a heterogeneous subculture in opposition to society is too simplistic. Rock climbing as a subculture is complex, not least because of the "flux and constant state of proliferation" (Jenks 2005: 135) caused through contemporary adapted rock climbing environments and activities. Despite this, rock climbing remains adventurous (Lewis, 2004; Donnelly 2003; Heywood, 1994) and still differs significantly from wider societal culture (see Varley, 2006; Simmel, 1991 and also Beck 1992 for a general societal overview). But it is the tensions within rock climbing and their effect on rock climbing practice and subculture that is of interest in this chapter.

\section{SUBCULTURAL DIFFERENTIATION}

Contemporary climbing types are differentiated. They consist of different types of climbing (bouldering, indoor climbing, sport climbing, deep water soloing). They differ in their approach to traditional climbing and because their proliferation and accessibility are being accepted as the way to climb. Luhmann (1996: 60) conceptualises differentiation by sugesting "a pre-formed" system can be delimited from the environment to form its own 
environment for new subsystems. Here my interpretation of differentiation is the assumption that traditional climbing is the "pre-formed" "delimited" subsystem for contemporary climbing types. The autonomy of these 'new ways' of contemporary climbing requires consideration, not least in order to be developed as products in themselves for adventure tourism operators.

Contemporary climbing practices are becoming more acceptable within traditional climbing and a shift in climbing values towards contemporary forms of climbing may be identified. Luhmann (ibid) goes on to suggest that eventually a subsystem is able to "observe its own operations" and "monitor its own cohesion" as opposed to being reliant on the "pre-formed system". In effect, he suggests that new autonomous values and norms are created within the “pre-formed system". These new value systems in rock climbing align themselves more readily with societal values giving weight to Hebdige's (1987) subcultural appropriation theory. Figure 3 represents this schematically and shows the importance of differentiation in the overall demise of a strong counter or subculture. To provide imagery to help with this explanation Smith (2011) showed aerial film of the breakup of ice shelves in the Antarctic. As a unified whole the ice shelf is protected but once fragmented (or differentiated) each section is subsumed into the southern ocean. Such changes only occur given the right frame (environmental) conditions.

A further way of depicting traditional and contemporary rock climbing approaches in the UK and their alignment with society is to use Young's (1997) theory of subterranean values. Its framework will focus solely on the micro-culture of climbing rather than its intended purpose to compare and contrast values of the wider urban society with subculture. Young (1997: 73) discussed subterranean values seeing these as more likely to be expressed in alternative 
leisure settings. Examples might be wind surfing and skate boarding (See Wheaton, 2000, 2004, Beal 1995). Table 1 depicts these contrasted values.

\section{INSERT TABLE 1}

Using the problematic dualistic approach of contemporary sport and traditional climbing adopted by other academics (Donnelly 2003; Heywood 1994, 2006; Lewis 2000, 2004), Young's typology shows wide disparity of climbing values and manifest practice. 'The formal work values' could easily be attached to more contemporary approaches adopted by sport climbers. A second table of values may be produced.

\section{INSERT TABLE 2}

Similarly in turning attention to subterranean values these could easily be linked to traditional climbing approaches.

\section{INSERT TABLE 3}

Contemporary forms of the activity (bouldering, indoor and sport climbing) are more easily aligned to macro-social values than traditional climbing and therefore more readily influenced by society and appropriated by non-climbers. The result is institutionalisation and regulation of different aspects of the activity. Without this adventure tourism would find the natural unpredictability of climbing difficult to manage. While appropriation may be associated with demise of the more subcultural elements of climbing such as danger, unpredictability and risk it allows its use as an adventure tourism activity to develop.

\section{OUTDOOR APPRENTICESHIPS}

A further outcome of contemporary climbing practice is the demise of a holistic skill set enabling independent and autonomous enjoyment of rock climbing. Donnelly recognised specific teaching techniques being used in climbing as early as 1985 . Such practices have grown and courses and Master classes are common. Heywood (1994) argues that all types of climbing are now sanitised and rationalised. In this he includes traditional climbing and 
suggests it is rationalised through the equipment, information available and training techniques deployed (Heywood, 1994). He also argues that the difference between sport climbing and traditional climbing is becoming less obvious:

Sport climbing and adventure climbing as it is practised by most people most of the time are not separated by an unbridgeable chasm; they are already closely related, and this suggests, worryingly from the point of view of those who value the 'British approach', that the spread of sport climbing can be seen quite reasonably as a natural development in climbing practice generally (Heywood, 1994: 191).

This rationalisation is supported by the frame conditions. We are technologically driven: equipment is important both practically and aesthetically, time is precious and there is a need to utilise it wisely favouring contemporary climbing practices. Access to climbing areas has improved and sport climbing crags with easier grades are regularly used by increasing numbers of climbers and groups. Indoor climbing centres continue to be developed showing demand is still buoyant (BMC, 2003). There are a growing number of outdoor operators in the UK (ibid) and guided trips seem to be more commonplace in UK and European mountains.

Contemporary climbers are realising hardship and long outdoor climbing apprenticeships are no longer necessary with the advent of modern facilities. Climbers become fit and stay fit indoors. They can learn to belay and lead climb and have sufficient skill to render climbing safe on pre-placed equipment. An outdoor environment offering sport climbing can therefore be the beginnings of outdoor experience. Even climbing outdoors in such circumstances may be seen as a closed environment in that, as much as possible, the crag has been rendered safe. 
Sport crags tend to be in reasonably accessible; others may frequent the crag and it could be viewed as an extension of indoor practices. The responsibility for safety has shifted to the professionals who develop indoor and outdoor facilities for commercial gain and the love of the sport. Such issues bring into question the place of the traditional outdoor climbing apprenticeship (see Figures 3 and 4).

There is little need for long outdoor apprenticeships in contemporary climbing types. The outdoor apprenticeship is a realm of holistic outdoor experience where skills of map work, meteorology, geological, geographical and topographical knowledge as well as guidebook interpretation and specialist equipment knowledge all play a part in safe climbing practice and are firmly rooted in traditional climbing. At many traditional climbing venues the environment is less predictable, routes far more committing and specific skills are necessary for safe ascents. Rope work, placing and removing equipment, belaying safely, abseiling, route choice and anticipation of possible problems based upon knowledge and experience may all be prerequisites for traditional climbing. Self rescue, first aid and emergency protocols are essential. The onus is on a competent pair of climbers with equal skill and experience to deal with situations that may arise. For more contemporary climbing practices participants' fitness and flexibility combined with good technical skill are the only necessary requirements. Outdoor skills and knowledge required are minimal. There is little need for the type of extensive apprenticeship seen in traditional climbing. This is further confirmation of the sanitisation and rationalisation of other climbing forms when compared to traditional climbing (Heywood, 1994, Lewis, 2000, 2004).

A second outcome of such developments is a reiteration of Donnelly's professionalization of sporting activities (see Donnelly, 1985: 44). Questions of safety within contemporary 
climbing types are largely left to the 'professional climber': frequency and quality of fixed protection, configuration of belays and lower off points are all decided beforehand (see

Oliver, 2006). In some instances even stability of the rock and therefore safety of the climbing venue is the result of extensive cleaning and preparation by local activists. Climbers may even come to expect this level of attentiveness and preparation if their general experience of climbing is indoors. Concern within this outcome is also raised due to the increasingly litigious nature of British society and ensuing blame culture.

Differing levels of knowledge, experience and outdoor skill acts as a segregator between outdoor enthusiasts and those seeking the physical challenge of rock climbing. Representations of the apprenticeship process in traditional and more contemporary climbing practices are depicted in Figures 3 and 4.

\section{OUTCOMES OF MERGING STYLES AND FRAME CONDITIONS}

Leisure lifestyles are symbols and definers of who we are (Wheaton, 2004). The last two decades have seen the outdoors carrying more cultural capital (Bourdieu, 1986) in Western societies. This is underpinned by a $\$ 220$ billion spend in the US alone on adventure tourism travel and related products (Adventure Travel Society, 1999 in Cater, 2007: 63). In the UK, Campbell, Greenwood and Yeoman (2007) reported a direct spend in 2003 of $£ 631$ million on adventure breaks to Scotland alone. Secondary spend is generated from many prestigious events based in Scotland. For example, the UCI Mountain Bike World Cup held annually at Fort William has an estimated associated spend of $£ 2$ million (Campbell et al, 2007: 7). Scotland has established itself as Europe's adventure capital with numerous outdoor adventure activities well established. 
Rock climbing in the UK is considered an important facet of adventure tourism for many adventure tourism operators. Buckley (2007: 1428) gives a product oriented definition of adventure tourism as "guided commercial tours, where the principal attraction is an outdoor activity that relies on features of the natural terrain, generally requires specialised equipment, and is exciting for the tour client". While not considering the popularity of multi activity adventure holidays now offered by organisations in the UK such as the Youth Hostel Association and the many individual operators, it does emphasise the specialist nature of the adventure tourism industry and the product it offers. Multi day journeys in the UK are less popular than in other countries where more extensive wilderness travel and settled weather is an attraction. Popular adventure activities in the UK such as scrambling, gill scrambling, canyoning, coasteering, abseiling, caving and mine exploration all use specialist equipment and skills from rock climbing.

Indoor climbing walls and bouldering centres have increased dramatically in the past two decades (British Mountaineering Council [BMC] 2003) and an increase in visitor numbers obviously accompanies this. "Indoorisation" (Bottenburg \& Salome 2010) of the outdoors allows safe practice of rock climbing in an artificially created environment where with rudimentary skills anyone can participate. This, coupled with a proliferation of glossy magazines, block buster films, advertising through climbing, on line information and chat rooms has led to more general climbing accessibility. Its status as a counter cultural activity only for those who have amassed the knowledge, skill and experience to operate in the vertical environment has diminished considerably and main streaming has occurred. Beedie and Hudson (2003) provide examples of this in mountaineering where money will buy a summit almost regardless of climbing experience see also Bullock 2011) Beedie and Hudson (2003: 625) suggest evidence is available to show "a dilution of the essential ingredients of 
'being a mountaineer' as a result of the democratisation process facilitated by the arrival of some urban characteristics in wild mountain areas" is occurring. The outdoors and involvement in lifestyle sports (Wheaton, 2004) is an important thread in the weaving of a personal tapestry attractive to others. Ensuring a positive personal profile on web based social sites such as face book is an important objective and the outdoors may help in this process. Such changes will only occur given synergy between rock climbing and its frame conditions.

The following two examples from contemporary climbing practices emphasise the importance of this synergy in order for significant change to occur. Bouldering is not a contemporary activity. Guidebooks show photographs of climber's bouldering as early as the beginning of the twentieth century. But it has never captured the imagination of climbers as an activity in its own right until the frame conditions came together to allowed bouldering to appeal to contemporary climbers. The style and branding of bouldering as a 'freestyle' activity akin to other outdoor sports such as surfing has occurred (see Barkham, 2006, Buckley, 2003). It suits the busy, 'quick fix', often fragmented lifestyle of the twenty first century (Roberts, 1999) and offers quality time with friends. It is popular because of dovetailing that occurs with changes experienced in society and the coming together of the right conditions at the right time in order for bouldering to flourish.

The second example concerns issues of globalisation. Climbing no longer has to be an isolated activity involving two people. Global networking ensures a voice can be given to any climbing occurrence. Web forums, chat rooms and personal or shared web pages mean instant access to climbing information and events (Barkham, 2006). Global networks also mean a shrinking world where climbers are able to quickly access climbing venues through cheap air travel and a network of services specifically aimed at the climber. Readily available 
information on climbing conditions allows focused forays into the mountains knowing that routes will be available to climb.

Relationships in climbing have changed not least because of the World Wide Web, but so too have the relationship between climbers and society more generally. The outdoors is cool: it brings with it a positive 'feel good' factor recognised by many through the proliferation of imagery now available. Rock climbing is synonymous with the outdoors and can now be accessed by all. Hardwell's (2007) research reveals the most likely introduction to climbing for many younger participants to be a birthday party. Campbell el al (2007) cite stag and hen parties as being important client groups supporting the adventure tourism market. Donnelley (1993: 127) observed that climbing is a resilient sub-culture because "it has existed for so long as an alternative to mainstream sport, an unincorporated and self governing parallel to the dominant sport culture". However, he also suggested its resilience "appears to be coming to an end" (ibid) and such examples underpin these thoughts.

\section{THE SIGNIFICANCE FOR ADVENTURE TOURISM}

The changes documented suggest a loss of traditional climbing. There are more people climbing but less interest in the traditional style of climbing which has been the main stay of UK rock climbing for a century. But with change and new ways of practicing rock climbing come opportunities. Commercially oriented activity in the outdoors relies on identifying and then minimising the actual risks involved while recognising client risk perceptions may be high (Priest, 1990, Mortlock, 1984). Capitalising on perceived risk allows for high customer satisfaction and possible repeat business (Campbell et al, 2007). INSIGHTS (2003) provided four categorisations of adventure tourists allowing for client differentiation. Samplers, learners and dabblers may all be more easily catered for using perceived rather than actual 
risk situation. Here contemporary rock climbing practices may be used to develop personal rock climbing skills safely. However, the fourth client group category, the enthusiasts, require careful consideration as experience often brings with it a requirement for more demanding activities (Buckley, 2011).

Understanding client differentiation and their motivations is important in developing an adventure tourism package that meets the expectations of the client. This may be more important in adventure tourism than any other tourism service offered and, because of the open environment in which services are offered, may be more difficult to fulfil. Buckley's (2011) table of adventure activity motivations is adapted in Table 4 to show how a common contemporary climbing practice of top roping climbs in the outdoors may be fulfilling for samplers, learners and dabblers but leave the enthusiast wanting a more challenging (authentic) experience (Hardwell, 2009). Using this will further highlight how changes in rock climbing practices and accessibility will aid the provision of meaningful experiences for some but not all client groups in adventure tourism. Importantly, the enthusiasts are less likely to require direct service provision from outdoor centres and professionals because they may already own the equipment and have acquired some skills in the activity (Campbell et al, 2007). It is the samplers, learners and dabblers who may be directly introduced to rock climbing through outdoor centres and professionals. An introduction using any of the contemporary methods highlighted (bouldering, indoor climbing [to a lesser extent], bottom rope climbing on accessible climbing venues) will provide a meaningful experience for the samplers and dabblers and build essential skills for the learners. Accessibility of these venues and introductory options has increased dramatically in the last two decades. 
The uniqueness of rock climbing as an adventure activity (and outdoor activities more generally) stems from providing challenge regardless of ability or skill. Most people recognise the inherent risk of heights and to defy gravity trusting only a single rope and a climbing partner provides a thrilling experience. Risks can be minimised, perhaps negated when using indoor venues and the activity can be developed as a meaningful adventure tourism experience, particularly for less experienced outdoor participants.

Physical accessibility is important for adventure tourism operators but so too is social accessibility. Climbing now has a much broader following and fewer are taking Scott's (1994) stance of the importance of an apprenticeship in the mountains. The fast tracking nature of gaining access to the high mountains is never more prevalent than in the Himalaya (Beedie \& Hudson, 2003). To an extent this has demystified climbing and mountaineering as an activity and ensured access to far wider participants. The older traditional climber is seen next to the sampler during the dark winter months as each participant meets their motivations at the indoor climbing wall. Marchart (2004) discusses appropriation and this is particularly important to UK rock climbing in the $21^{\text {st }}$ century. Rock climbing subculture is becoming far more penetrable and fluid around its fringes allowing more people to be involved in the activity and enjoy movement on rock in safe yet absorbing situations (see Hardwell, 2009).

Adventure tourism in the UK seems characterised more by short term multi activity breaks fitting into Rubens (1999) 'narrow' view of adventurous activities. For example, registered multi activity break providers make up $16 \%$ of registered provision providing direct adventure services to clients in Scotland (Campbell et al, 2007: 3). But more research is required into the independent adventure enthusiasts who constitute up to $72 \%$ of the adventure tourism market (ibid: 11). What is changing markedly are the client groups 
enjoying adventure tourism. "There are signs that activity holidays are no longer just the preserve of young adrenaline junkies, but are becoming more 'mainstream', attracting more women, more over-50s and more families" (Mintel, 2010: 1). A more European feel to rock climbing as a social activity for all family members would allow even greater accessibility and such an approach is already being seen in many indoor climbing venues and mountain biking areas where cafes are also a feature of services offered.

\section{CONCLUSION}

Understanding rock climbing as a multifaceted activity has served two purposes in this chapter. Subcultural theory has allowed a critical evaluation of how this process has occurred but, more pragmatically, the importance of understanding the array of market and business opportunities available through the process of differentiation has been highlighted. These changes in rock climbing are a result of wider societal changes or frame conditions that shape any activity (Hargreaves, 1986. Maffesoli (2000: 73) states that "in each era, a type of sensibility predominates; a style which specifies the relationships we forge with others". This sensibility predominates within subcultures and between society and subcultural groups. Rock climbing as an activity is becoming more widely accepted through the process of appropriation (Marchart 2003, Hardwell 2007) and this opens up commercial opportunity and while the samplers, learners and dabblers may enjoy the appropriated forms of rock climbing and satisfy their motivations for involvement in adventure tourism, the enthusiasts will want a climbing experience more close to the core function of rock climbing.

For the seasoned climber the core purpose of rock climbing will remain unchanged. There will always be opportunity for traditional climbing practices with the UK still remaining the bastion of traditional climbing style worldwide. But there is also a requirement to let go, to 
embrace change, to decide what can be given over to those who wish to experience similar thrills and excitement that have kept many involved in rock climbing for a life time. This is already happening thoughtfully and successfully in many indoor climbing centres. Different user groups with very different agendas coexist quite happily. The changes have brought more employment opportunities for those dedicated to the outdoor and adventure tourism continues to thrive despite the recession (Mintel, 2010). The change in rock climbing practice over the past three decades and the dedication of local activists in overseeing sensible venue development will ensure rock climbing remains an important inclusion in the suite of activities offered by adventure tour operators without compromising its traditional roots. In embracing the inevitable changes occurring in many leisure pursuits it is worth considering the balance between the new and the traditional. Such thoughts are neatly captured in the following passage by Beck (1992).

We need ideas and theories that will allow us to conceive the new which is rolling over us in a new way, and allow us to live and act with it. At the same time we must retain good relations with the treasures of tradition. (Beck 1992: 12)

Present frame conditions now, more than any other time, favour the outdoors as a place for recreation, enjoyment, escape and excitement and because of this there is more opportunity for outdoor. Adventure tourism has quickly capitalised on contemporary climbing practices, not least through indoor climbing centres. But I see few reasons why we need to forge ahead with the new while neglecting the traditions that have been instrumental in bringing us to where we are now. There is no reason why we cannot develop the best of both worlds. We can provide opportunity for growth in the new yet still underpin traditions of the past. As potential providers of adventure tourism experiences we do have a responsibility to our 
clients, employees and the environment. There has to be a respect for how others before us have used and developed the activities in our portfolio. Simple ways of developing a culture of respect for traditional practices can make a difference to both staff and client experience. For example, the dates of a recent adventure tourism conference in Fort William purposefully coincided with the Fort William Mountain Film Festival and delegates were encouraged to access films of traditional climbing action spliced with contemporary forms of climbing practice.

Many of us working in outdoors have not decided to do so for its inevitable fame and fortune. Instead, we have an intrinsic love of the outdoors coupled with our own outdoor apprenticeships built through history and embracing tradition. Ensuring we share our experiences and practices regularly will enrich our own lives, the lives of participants and the programmes we develop. This heady mixture of appreciation of the outdoors through traditions, practical experience and skill development will help to ensure all participants take something meaningful from their adventure tourism experience. 


\section{REFERENCE LIST}

Barkham, P. (2006) A Bigger Splash a Bit More Cash, Guardian Newspaper, available [on line] at URL: http://www.travel.guardian.co.uk/news/stroy/),,1822297,00.htm accessed on 18-08-2006.

Beedie, P. and Hudson, S. (2003) Emergence of Mountain-based Tourism, Annals of Tourism Research, 30: (3), pp. $625-643$.

Beal, B. (1995) Disqualifying the Official: An Exploration of Social Resistance through the Subculture of Skateboarding, Sociology of Sport Journal, 12, pp.252-267.

Beal, B. and Crosset T. (1997) The Use of 'Subculture' and 'Subworld' in Ethnographic Works on Sport: A Discussion of Definitional Distinctions, Sociology of Sport Journal, 12, pp.252-267.

Beck, U. (1992) Risk Society: Towards a New Modernity, London: Sage.

Birkett, W. (1983) Lakeland's Greatest Pioneers: 100 Years of Rock Climbing, London: Robert Hale.

Bottenburg, M. and Salome, L. (2010) The Indoorisation of outdoor sports: an exploration of the rise of lifestyle sports in artificial settings, Leisure Studies, 29: (2) pp. 143 - 160. Bourdieu, P. [transcript Nice, R]. (2001 [1986]) Distinction: A Social Critique of the Judgement of Taste, London: Sage.

British Mountaineering Council (BMC) (2003) Participation Statistics, available [on line] at URL:http://www.thebmc.co.uk/safety/advice/articles/ParticipationStatistics03.

pdf. accessed on 23-9-2003.

Buckley, R. (2011) Rush as a key motivation in skilled tourism: Resolving the risk recreation paradox, Tourism Management, 30, pp. $1-10$.

Buckley, R. (2007) Adventure Tourism Products: price, duration, size, skill, remoteness, Tourism Management, 28, PP. 1428 - 1433. 
Buckley, R. (2003) Adventure Tourism and the Clothing, Fashion and Entertainment Industry, Journal of Eco-tourism, 2, (2), pp.126-136.

Bullock, N. (2011) Mountains for Sale, Summit Magazine, 63, Autumn, pp. 32 - 36.

Campbell, E., Greenwood, C. and Yeoman, I. (2007) Visit Scotland: What will activity and adventure tourism look like in 2015? Report compiled for and published by Visit Scotland. Cater, C. I. (2007) Adventure Tourism: will to power? In A. Church and T. Coles [eds], Tourism, Power and Space, Abingdon, Oxon: Routledge, pp. 63 - 82.

Donnelly, P. (2003) The Great Divide Sport Climbing vs. Adventure Climbing, in To the Extreme: Alternative Sports, Inside and Out, R. E. Rinehart, and S. Sydnor (eds), Albany: State University.

Donnelly, P. (1993) Subcultures in Sport: Resilience Transformation, in Sport in Social Development: Traditions, Transitions and Transformations., A. G Ingham, and J. W. Loy (eds) Champaign, Illanois: Human Kenetics, pp.119-145.

Donnelly, P. (1981) Towards a Definition of Sport Subculture, in Sport in the Sociocultural Process, M. Hart and S. Birell, Iowa: Wm. C. Brown, pp.465-587.

Donnelly, P. and Young, K. (1988) The Cosntruction and Confirmation of Identity in Sport Subcultures, Sociology of Sport Journal, 5, pp.223-240.

Drasdo, H. (1996) The Ordinary Route, Berwick: The Ernest Press.

Gelder, K. and Thornton, S. (eds) (1997) The Subcultures Reader, London: Routledge.

Gray, D. (1993) Slack: The Fun of Climbing, Dewsbury: Joseph Ward.

Gray, D. (1993a) Tight Rope! The Fun of Climbing, Berwick: The Ernest Press Hankinson, A. (1988) A Century on the Crags: The History of Rock Climbing in the Lake District, Frome, Somerset: Butler and Tanner Ltd. 
Hardwell, A. (2009) Authentic Experience: The Importance of Climbing to Indoor Only Climbers, in J. Ormrod and B. Wheaton, On the Edge: Leisure Consumption and the Representation of Adventure Sports, Brighton: LSA Publication 104, pp. 161 - 203. Hardwell, A. G. (2007) Detraditionalization and Differentiation in UK Rock Climbers, Unpublished PhD thesis, University of Central Lancashire.

Hargreaves, J. (1986) Sport, Power and Culture: A Social Historical Analysis of Popular Sports in Britain, London: Polity Press.

Hebdige, D. (1987) Subculture: The Meaning of Style, London, UK: Routledge.

Heywood, I. (1994) Urgent dreams: Climbing Rationalization and Ambivalence, Leisure Studies, 13, pp.179-194.

INSIGHTS (2003) Adventure Tourism Typology cited in Visit Scotland: What will activity and adventure tourism look like in 2015?, E. Campbell, C. Greenwood, and I. Yeoman (2007) Report compiled for and published by Visit Scotland.

Jones, T. and Milburn, G. (1988) Cumbrian Rock: 100 Years of Climbing in the Lake District, Manchester: Pic Publications.

Jenks, C. (2005) Subculture: The Fragmentation of the Social, London: Sage.

Kiewa, J. (2002) Traditional Climbing: Metaphor of Resistance or Metanarrative of Oppression?, Leisure Studies, 21, pp.145-161.

Last, A. (1997) Causes and Solutions to Incidences of Climbing, unpublished Masters thesis, Sheffield Hallam University.

Lewis, N. (2004) Sustainable Adventure: Embodied Experiences and Ecological Practices within British Climbing, in Understanding Lifestyle Sports: Consumption, Identity and Difference, B. Wheaton (ed), Oxon, UK: Routledge, pp.70-93.

Lewis, N. (2000) The Climbing Body, Nature and the Experience of Modernity, Body and Society, 6, (3), pp.58-80. 
Lim, F. K. G. (2008) Of reverie and emplacement: spatial imaginings and tourism encounters in Nepal Himalaya, Inter Asia Cultural Studies, Vol. 9, No. 3, pp. 375 - 394.

Luhmann, N. (1996) Complexity, Structural Contingencies and Value Conflicts in

Detraditionalization, P. Heelas, S. Lash and P. Morris (eds), Oxford: Blackwell, pp.59-71.

Macbeth, J. (2005) The 'Pals' the 'Professionals' and the 'Conformers': The meaning of Football in the Lives of Women Footballers in Scotland, in The Bountiful Game? Football Identities and Finances, J. Magee, A. Bairner, and A. Tomlinson (eds), Oxford: Meyer and Meyer Sport, pp.79-97.

Maffesoli, M. (2000) The Time of Tribes: The Decline of Individualism in Mass Society, London: Sage.

Marchart, O. (2004) Bridging the Micro-Macro Gap: Is there Such a Thing as a Postsubcultural Politics?, in The Post Subcultural Reader, D. Muggleton and R. Weinzierl (eds), Oxford, UK: Berg, pp.83-100.

Mortlock, C. (1984) The Adventure Alternative, Milnthorpe, England: Cicerone Press. Mintel (2010) Activity Holidays - UK - 2010, Mintel, Oxygen.

Oliver, S. (2006) Moral Dilemmas of Participation in Dangerous Leisure Activities, Leisure Studies, 25, (1), pp.95-109.

Perrin, J. (2004) The Villain, London: Hutchinson.

Roberts, K. (1999) Leisure in Contemporary Society, Oxon, UK: CABI Publications. Rubens, D. (1999) Effort or Performance: Keys to motivated learners in the outdoors, Horizons, 4: pp. $26-28$.

Priest, S. (1990) The Adventure Experience Paradigm, in Adventure Education, J. Miles and S. Priest (eds), State College, PA: Venture Publishing, pp. 157 - 162.

Poon, A. (1993) Tourism Technology and Competitive Strategy, Willingford: CAB International. 
Simmel, G. (1997 [1991]) The Adventure, in Simmel on Culture, D. Frisby and M.

Featherstone (eds) London: Sage Publications, pp.221-233.

Scott, D. (1999) Trekking Commentary, High Magazine, 134: pp. 56 - 59.

Smith, A. (2011) The Frozen Planet, BBC television documentary.

Varley, P. (2006) Adventurers in Bohemia: Temporary Adventure Communities in the

'Forgotten Ground' of Late Modernity. Paper presented to the Leisure Studies Association Annual Conference, Making Space: Leisure, Tourism and Renewal.

Wheaton, B. (2004) Introduction: Mapping the Lifestyle Sport-scape, in Understanding

Lifestyle Sports: Consumption, identity and difference, B. Wheaton (ed), Abingdon Oxon UK: Routledge, pp.1-28.

Wheaton, B. (2000) 'Just Do It': Consumption Commitment, and Identity in the Windsurfing Culture, Sociology of Sport Journal, 3, pp.254-276.

Weinzierl, S. and Muggleton, D. (2004) What is Post-Subcultural Studies' Anyway? in The Post-subcultures Reader, Oxford, UK: Berg, pp.3-26.

Wilson, K. (1998) A Future for Traditional Values, The Alpine Journal, 103, (357), pp.175188.

Young, J. (1997 [1971]) The Subterranean World of Play, in The Subcultural Reader, K.

Gelder and S. Thornton (eds), London: Routledge, pp.71-80. 